\title{
SEROLOGICAL DIFFERENTIATION OF MICROSPORIDIA WITH SPECIAL REFERENCE TO TRACHIPLEISTOPHORA HOMINIS
}

\author{
CHENEY S.A.*, LAFRANCHI-TRISTEM N.J.* \& CANNING E.U.*
}

\section{Summary :}

Myositis is a common clinical syndrome in advanced stages of AIDS. Trachipleistophora hominis (phylum Microspora) has been detected in several cases of painful, immobilising myositis in AIDS patients. Enzyme linked immunosorbent assays (ELISAs) and Western blotting of protein profiles separated by SDS PAGE were used to determine whether this species could be detected and differentiated by serology. Sixteen microsporidia, including several species known to infect man and species infecting fish,

crustaceans and a mosquito, were used as antigen. Each species had a unique profile of SDS PAGE-separated proteins. In Western blots, mouse antiserum, raised to $T$. hominis and selected for its high ELISA specificity, bound to antigens ranging from less than $25 \mathrm{kDa}$ to greater than $250 \mathrm{kDa}$ with major bands at $39-44 \mathrm{kDa}$ and $98-150 \mathrm{kDa}$ on $T$. hominis protein profiles. The serum also recognised some high molecular weight antigens in the profiles of Vavraia culicis, Heterosporis anguillarum, and three species of Pleistophora but none in the remaining genera examined. It was concluded that ELISA and Western blotting could be used to detect and differentiate $T$. hominis in muscle biopsy tissue from patients with myositis. However, sera from T. hominis-infected patients in the terminal stages of AIDS would not be useful for detection of infections because of a sharp decline in antibody level.

KEY WORDS : Trachipleistophora hominis, microsporidia, human myositis, fish, crustaceans, mosquitoes, ELISA, SDS PAGE, Western blot.

\section{INTRODUCTION}

T The microsporidian parasite Trachipleistophora bominis Hollister, Canning, Weidner, Field, Kench \& Marriott, 1996 was found infecting the skeletal muscle and cornea and was present in nasal discharge of an AIDS patient (Field et al., 1996). The patient had become immobilised by severe muscular pain and wasting but his condition improved after treatment with a therapeutic combination which included albendazole (400 mg twice daily), a drug with known anti-microsporidial activity. The patient died five

\footnotetext{
* Department of Biology, Imperial College of Science, Technology and Medicine, London SW7 2AZ, U.K.

Correspondence: Elizabeth U. Canning, Imperial College at Silwood Park, Ascot, Berks SL5 7PY, U.K.

Tel.: 02075942244 - Fax: 02075942339

E-mail: e.canning@ic.ac.uk
}

Résumé : DIFFÉRENCIATION SÉROLOGIQUE DES MICROSPORIDIES ET NOTAMMENT DE TRACHIPLEISTOPHORA HOMINIS

La myosite est un syndrome fréquent des stades avancés du SIDA. Trachipleistophora hominis (phylum Microspora) a été détecté dans plusieurs cas de myosite douloureux, immobilisant les patients atteints du SIDA. L'ELISA et le Western blot des protéines séparées par SDS PAGE ont été utilisés pour déterminer si cette espèce peut être détectée et différenciée par sérologie. Outre T. hominis, quinze autres espèces trouvées respectivement chez l'homme, des poissons, des crustacés ou des moustiques ont été utilisées comme matériel antigénique. Le profil des protéines séparées par le SDS PAGE était propre à chaque espèce. En Western blot, un sérum de souris dirigé contre $T$. hominis et choisi pour sa haute spécificité en ELISA s'est lié à des antigènes compris entre $<25 \mathrm{kDa}$ et $>250 \mathrm{kDa}$ avec des bandes principales à 39$44 \mathrm{kDa}$ et 98-150 kDa dans les profils de protéines obtenus à partir de $T$. hominis. Ce même sérum a également reconnu des antigènes de haut poids moléculaire de Vavraia culicis, d'Heterosporis anguillarum et de trois espèces de Pleistophora mais aucun dans les autres genres testés. En conclusion, I'ELISA et le Western blot peuvent être utilisés pour détecter et différencier T. hominis dans les biopsies musculaires des patients atteints de la myosite. Toutefois, le sérum des patients contaminés par cette microsporidie aux stades terminaux du SIDA serait inutilisable pour sa détection en raison de la chute du taux des anticorps sériques.

MOTS CLÉS : Trachipleistophora hominis, microsporidies, myosite humaine, poisson, crustacé, moustiques, ELISA, SDS PAGE, Western blot.

months after admission to hospital of progressive HIV disease without recurrence of myositis. The microsporidia were isolated in vitro and described as a new genus and species (Hollister et al., 1996).

In numerous genera of microsporidia, sporogony culminates in a large (more than eight) and variable number of spores packaged in an envelope of presumed parasite origin (polysporous in sporophorous vesicles). Of these only Trachipleistophora from man and Glugea, Heterosporis and Pleistophora from fish are known from vertebrates Pleistophora-like microsporidia also infect edible crustaceans - shrimps and crabs. Glugea and Heterosporis infections are strictly localised in their hosts by being retained within hypertrophied host cells modified to form xenomas. Pleistophora and Trachipleistophora infections are diffuse. Species of the genera Loma and Spraguea are also parasites of fish. In Loma, sporogony gives rise to four or more spores retained within a parasitophorous vacuole bounded by 
a membrane of presumed host origin (Lom \& Pekkarinen, 1999). In Spraguea there are two sporogonic sequences which give rise to two types of spores, both lying free in host cell cytoplasm (no enveloping membrane).

In two cases of microsporidian myositis in AIDS patients, the parasites were identified as Pleistophora spp. (Chupp et al., 1993; Grau et al., 1996) but are more likely to belong to Trachipleistophora than Pleistophora (Canning, 2001) and another T. hominis infection has been diagnosed recently (A. Curry, personal communication). A second species Trachipleistophora anthropophthera has caused a multisystem disseminating infection, especially infecting the brain, in two more AIDS patients (Yachnis et al., 1996; Vavra et al., 1998). The occurrence of several of these deep tissue infections, which cannot be transmitted directly between humans, at least not from muscle or brain, has raised the question of their origin, and ingestion of infected fish or crustaceans seemed a likely possibility. However, in a recent study of generic relationships revealed by a molecular phylogeny, Vavraia culicis a parasite of anopheline and culicine mosquitoes was found to be closest to $T$. bominis, raising the possibility of microsporidian myositis being a vector-borne disease (Cheney et al., 2000). All the Trachipleistophora infections so far detected have been at an advanced stage, only investigated because of the pain and weakness of muscles suffered by the patients. Buskila \& Gladman (1990) reported that $35 \%$ of AIDS patients suffer some degree of myositis. In this paper we report on an approach to serological detection of $T$. hominis and differentiation of polysporous microsporidia by enzyme linked immunosorbent assay (ELISA) and Western blotting. These tests might be developed further to detect early infections of $T$. hominis in man and thus evaluate its role as a cause of myositis in AIDS patients.

\section{MATERIALS AND METHODS}

\section{ANTIGEN}

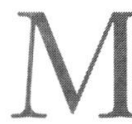
icrosporidia, spores of which were tested for cross reactivity with $T$. hominis in ELISAs, Western blots or both, are listed with their hosts in Table I. Those of human origin were propagated in vitro in the authors' laboratory after previous isolation from human tissue. Vavraia culicis was propagated in large lepidopteran larvae and purified spores were provided by courtesy of Dr J.J. Becnel. The other microsporidia, of fish, crustacean or insect origin, were obtained from their natural hosts, either as purified spores or infected host tissues. Spores were purified from culture supernatants or by mechanical disruption of host tissue, then lysis of host cells in water for one hour. The lysate was spun at $500 \mathrm{~g}$ for $10 \mathrm{~min}$, the pellet was resuspended in Minimal Essential Medium (MEM) and spun on a $50 \%$ Percoll gradient in PBS at $900 \mathrm{~g}$ for $30 \mathrm{~min}$. After washing three

\begin{tabular}{|c|c|c|c|}
\hline Microsporidia & Hosts & ELISA $^{1}$ titre & Western blot ${ }^{2}$ \\
\hline Trachipleistophora bominis & Homo sapiens $(\operatorname{man})^{3}$ & 12,800 & + \\
\hline Vavraia culicis & Aedes albopictus (mosquito) ${ }^{4}$ & $800 / 1,600$ & + \\
\hline Heterosporis anguillarum & Anguilla japonica (eel) & 200 & + \\
\hline Pleistophora hippoglossoideos & Hippoglossoides platessoides (dab) & 400 & ND \\
\hline Pleistophora mirandellae & Rutilus mutilus (roach) & 800 & $+1-$ \\
\hline Pleistophora typicalis & Myoxocephalus scorpius (bull rout) & 400 & + \\
\hline Pleistophora sp. (TB) & Taurulus bubalis (sea scorpion) & 200 & + \\
\hline Pleistophora sp. (LS) & Litopenaeus setiferus (shrimp) & 800 & - \\
\hline Pleistophora sp. (FA) & Farfantepenaeus aztecus (shrimp) & 400 & ND \\
\hline Spraguea lophii & Lophius americanus (angler fish) & 200 & - \\
\hline Glugea anomala & Gasterosteus aculeatus (stickleback) & ND & - \\
\hline Loma acerinae & Gymnocephalus cernuus (ruff) & ND & - \\
\hline Encephalitozoon cuniculi & Canis familiaris $(\mathrm{dog})^{5}$ & 800 & - \\
\hline Encephalitozoon bellem & Homo sapiens $(\operatorname{man})^{6}$ & 400 & ND \\
\hline Vairimorpha mesnili & Pieris brassicae (moth) & 200 & ND \\
\hline Vittaforma corneae & Homo sapiens (man) $)^{7}$ & 400 & ND \\
\hline
\end{tabular}

${ }^{1}$ ELISA titres are those obtained with mouse serum 483 (titre $=1: 12,800$ ).

${ }^{2}$ Western blotting was carried out with serum 443 (titre $=1: 3,200$ ). Results are given as positive $(+$ ), negative $(-)$ or borderline $(+/-$ ). ND $=$ not done.

${ }^{3}$ Propagated in RK13 cells after isolation from human muscle (Hollister et al., 1996).

${ }^{4}$ Propagated in larvae of Helicoverpa zea (Lepidoptera).

${ }^{5}$ Propagated in MDCK cells after isolation from dog (Stewart et al., 1979).

${ }^{6}$ Wainwright isolate, propagated in MDCK cells from human nasal polyp (Hollister et al., 1993).

${ }^{7}$ Propagated in MDCK cells from human corneal biospy (Shadduck et al., 1990; Silveira \& Canning, 1995).

Table I. - Microsporidia and their hosts used in ELISA and Western blotting. 
times the spore pellet was resuspended in MEM and stored at $4^{\circ} \mathrm{C}$.

\section{ANTISERA}

Balb C euthymic mice were inoculated intraperitoneally (ip) or subcutaneously (sc) with $5 \times 10^{6}$ or $10^{7}$ whole or disrupted spores of $T$. hominis with or without the adjuvant monophosphoryl lipid A plus trehalose dicorynomycolate emulsion (MPL+TDM, Sigma). Two to four inoculations were performed according to responses of individual mice. Titres were determined by ELISA using the dilution which gave an optical density reading equivalent to twice that of the control (normal serum) at the starting dilution. A single sample of human serum from an AIDS patient with T. hominis infection was also tested, with normal human serum as control.

\section{ELISA}

Spores of each species were added at $2 \times 10^{5}$ spores per well $\left(4 \times 10^{5}\right.$ spores of Encephalitozoon cuniculi, which has smaller spores) in carbonate/bicarbonate buffer overnight at $4^{\circ} \mathrm{C}$. Non-adherent spores were removed with the buffer and the remainder fixed to the plate with a 1:1 mixture of ethanol and methanol. The blocking agent was $1 \%$ horse serum (HS) in PBS. Normal mouse serum (control) and mouse antiserum to $T$. hominis were serially diluted in $1 \% \mathrm{HS}$ in PBS from $1 / 200$ to $1 / 100,000$ and incubated with antigen for one hour at room temperature (RT). For visualization Vectastain ${ }^{\circledR}$ ABC-AP kits for mouse IgG (Vector Laboratories) and, in one experiment the kit for mouse IgM, were used according to the manufacturer's instructions and the optical densities were read $10 \mathrm{~min}$ and $30 \mathrm{~min}$ after addition of substrate in a Dynatek MR 60 Microplate reader. Controls were E. coli (strain JM109) as non-microsporidian antigen and coating buffer only in place of serum. Vectastain ${ }^{\circledR}$ ABC-AP kits for human IgG and, in one experiment, the kits for human IgM, IgA, IgE and kappa and lambda were used for visualising reactions of the human serum.

\section{SDS-PAGE}

$10^{8}$ spores of each species $\left(2 \times 10^{8}\right.$ spores of E. cuniculi) were suspended in $200 \mu \mathrm{l}$ of modified Laemmli reducing buffer $(50 \mathrm{mM}$ TRIS-HCl $\mathrm{pH}$ 6.8, $100 \mathrm{mM}$ dithriothreitol, $10 \%$ glycerol). Spores were disrupted in a bead beater (Biospec Products), $10 \%$ SDS was added and the sample was boiled for $5 \mathrm{~min}$, spun at $1,200 \mathrm{~g}$ for $10 \mathrm{~min}$ and the supernatant containing the soluble spore proteins was collected. A $10 \mu \mathrm{l}$ aliquot was used for determination of protein concentration (Protein Assay, BioRad). Bromophenol blue (0.1\%) was added to the remainder for SDS-PAGE in a BioRad mini-gel apparatus, using $4 \%$ polyacrylamide stacking gel and $10 \%$ reducing polyacrylamide separating gel. Samples were added as $10 \mu \mathrm{l}$ aliquots containing $0.5 \mu \mathrm{g}$ protein to the slots, as well as $5 \mu \mathrm{l}$ of a prestained 10$250 \mathrm{kDa}$ molecular weight protein standard (Amersham, Rainbow Catalogue). Gels were run in at $120 \mathrm{~V}$ for $5 \mathrm{~min}$ and at $70 \mathrm{~V}$ for a further $3^{1 / 2}$ hours. Gels were silver stained (BioRad).

\section{WESTERN BLOTTING}

Unstained proteins separated by SDS-PAGE were transferred electrophoretically to Blot PVDF paper, pore size $0.2 \mu \mathrm{m}$ (BioRad) in a Mini Trans Blot system (BioRad), for $1 \mathrm{~h}$ at $100 \mathrm{~V}$ at $5^{\circ} \mathrm{C}$ in running buffer ( $48 \mathrm{mM}$ TRIS $\mathrm{pH} 9.2,39 \mathrm{mM}$ glycine, $20 \%$ methanol). The paper with transferred proteins was dipped into methanol, incubated for $1 \mathrm{~h}$ in $5 \%$ non fat dry milk powder in PBS, washed in PBS and incubated overnight with mouse or human antiserum. Reactive proteins were detected with Vectastain ${ }^{\circledR}$ ABC-AF kit (Vector Laboratories).

\section{RESULTS}

\section{TITRES OF MOUSE SERA}

$\mathrm{U}$ Ssing different combinations of inoculation route (ip or sc), whole or disrupted spores of $T$. hominis, with or without MPL + TDM, it was determined that whole spores inoculated i.p. stimulated a good antibody response, if given with adjuvant. The titres and details of inoculation are given in Table II. Serum from mouse 485 was virtually non-reactive and was discarded.

\section{ELISA}

Antiserum 483 with a titre of $1: 12,800$, was used to test cross reactivity with the full range of microsporidia available. The titres are given in Table I and show that the serum was strongly reactive on $T$. hominis and had some cross reactivity with several of the other species tested. It was at least eight times more reactive for IgG with $T$. hominis antigen $(1: 12,800)$ than with $V$. culicis (1:800-1,600). Reactivity was less on Pleistophora mirandellae, Pleistophora sp. (LS) from Litopenaeus setiferus and E. cuniculi (1:800), Pleistophora hippoglossoideos, Pleistophora typicalis, Pleistophora sp. (FA) from Farfantepenaeus aztecus, Encephalitozoon hellem and Vittaforma corneae (1:400) and was non-reactive on Heterosporis anguillarum, Pleistophora sp. (TB) from Taurulus bubalis, Spraguea lophii and Vairimorpha mesnili. When tested for IgM on T. hominis, the titre of serum 483 was 1:800. Serum from the AIDS patient who had been infected with $T$. hominis gave a titre of 
1:800 for IgG in the homologous test but was negative for IgM, IgA, IgE, kappa and lambda light chains. As there had been some cross reactivity between serum 483 and most of the microsporidia tested, all the other sera that had been raised in mice against $T$. hominis except serum 485 (Table II) were retested using $T$. hominis and $V$. culicis as antigen, to assess cross reactivity with the latter. In this test, serum 483 was eight times more specific for $T$. bominis $(1: 12,800$ versus $1: 1,600$ ) but serum 443 , with a lower titre against $T$. hominis, showed the highest specificity i.e. 16x more reactive on $T$. hominis than on $V$. culicis $(1: 3,200$ versus $1: 200)$. The highest titre serum (486) had almost the lowest specificity for $T$. hominis being only twice as reactive on $T$. hominis as on $V$. culicis $(1: 25,800$ versus 12,800$)$. Serum 443 was selected for Western blotting because of its high specificity and because it revealed a greater number of bands than did other sera in preliminary Western blots (data not shown).

\section{SDS-PAGE AND WESTERN BLOTS}

The protein profiles of 11 microsporidia separated by SDS PAGE are shown in Figure 1. The bands revealed in T. hominis are a group of four or five between 100 and $70 \mathrm{kDa}$, one at $62 \mathrm{kDa}$, a group of three between 54 and $50 \mathrm{kDa}$, a major band at $44 \mathrm{kDa}$, others between 40 and $34 \mathrm{kDa}$, another major band at $32 \mathrm{kDa}$ and several below $30 \mathrm{kDa}$. A clear profile was not obtained for Pleistophora sp. (TB) from T. bubalis. All profiles were unique.

When identical protein profiles were blotted with mouse serum 443 (Fig. 2), major immunogenic antigens of $T$. hominis were displayed between 150 and $98 \mathrm{kDa}$ and between 44 and $39 \mathrm{kDa}$ and there were others above 250 , at $80,66,38,36,33$ and below $25 \mathrm{kDa}$. Cross reactive antigens were also demonstrated in V. culicis, P. typicalis, Pleistophora sp. (TB) from $T$. bubalis and $H$. anguillarum but there was no binding to the low molecular weight bands of these spe-

\begin{tabular}{|c|c|c|c|c|c|c|}
\hline Mouse & $\begin{array}{c}\text { Number } \\
\text { of spores } \\
\text { per inoculation }\end{array}$ & $\begin{array}{c}\text { Number } \\
\text { of inoculations }\end{array}$ & $\begin{array}{l}\text { Condition } \\
\text { of spores }\end{array}$ & Solution & Route & Titre \\
\hline 443 & $5 \times 10^{6}$ & 4 & whole & PBS & i.p. & 3,200 \\
\hline 445 & $5 \times 10^{6}$ & 4 & whole & $\mathrm{MPL}+\mathrm{TDM}$ & i.p. & 3,200 \\
\hline 447 & $5 \times 10^{6}$ & 4 & disrupted & $\mathrm{MPL}+\mathrm{TDM}$ & s.c. & 6,400 \\
\hline 483 & $1 \times 10^{7}$ & 2 & whole & MPL+TDM & i.p. & 12,800 \\
\hline 484 & $1 \times 10^{7}$ & 3 & whole & $\mathrm{MPL}+\mathrm{TDM}$ & i.p. & 12,800 \\
\hline 485 & $5 \times 10^{6}$ & 3 & whole & $\mathrm{MPL}+\mathrm{TDM}$ & i.p. & 200 \\
\hline 486 & $5 \times 10^{6}$ & 3 & whole & $\mathrm{MPL}+\mathrm{TDM}$ & i.p. & 25,600 \\
\hline
\end{tabular}

Table II. - Methods for raising antisera in mice against T. bominis and titres of the sera.

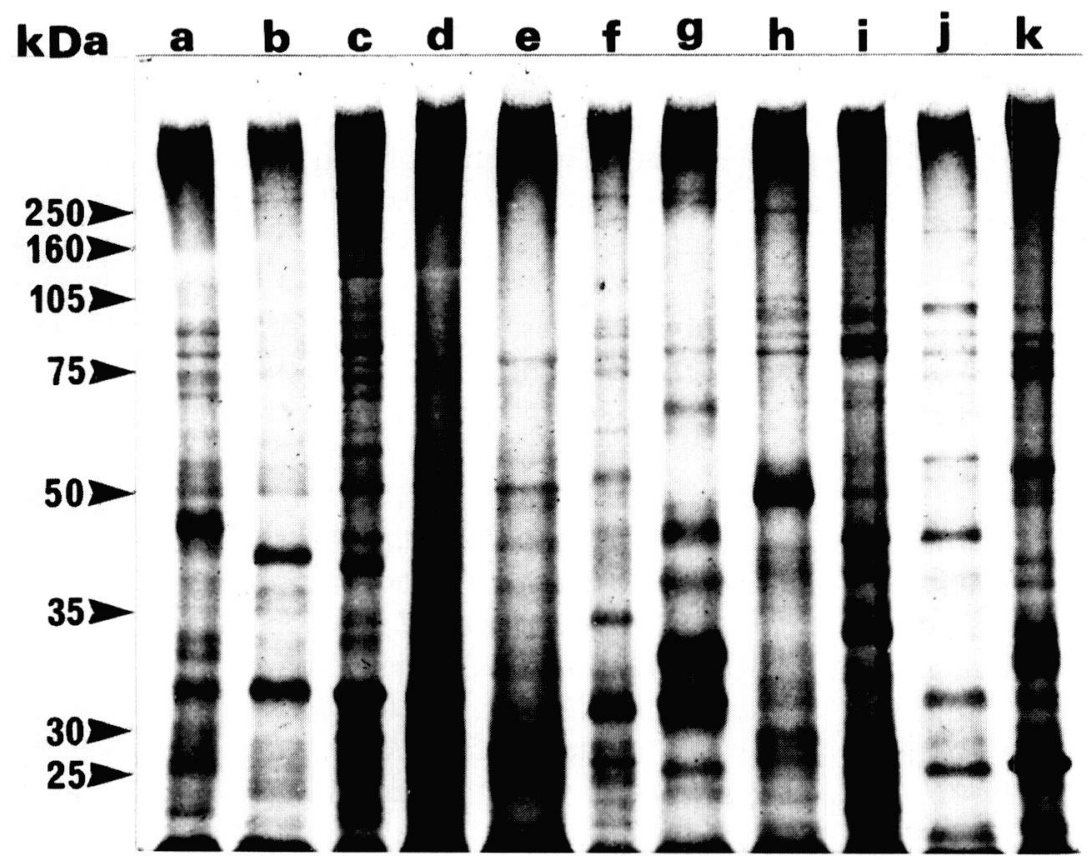

Fig. 1. - Silver-stained SDS-PAGE separated protein profiles of $T$. hominis in comparison with profiles of eleven microsporidia of fish, crustacean, insect and mammalian origin. Lanes are: a. Trachipleistophorus hominis, b. Vavraia culicis, c. Pleistophora typicalis, d. Pleistophora sp. (TB) from Taurulus bubalis, e. Heterosporis anguillarum, f. Pleistophora mirandellae, g. Pleistophora sp. (LS) from Litopenaeus setiferus, h. Glugea anomala, i. Loma acerinae, j. Spraguea lophii, k. Encephalitozoon cuniculi. 
Fig. 2. - Western blot of SDS PAGE-separated protein profiles of $T$. bominis and eleven other microsporidia with mouse antiserum 443 raised against $T$. hominis. Lanes a-k are as in Figure 1.
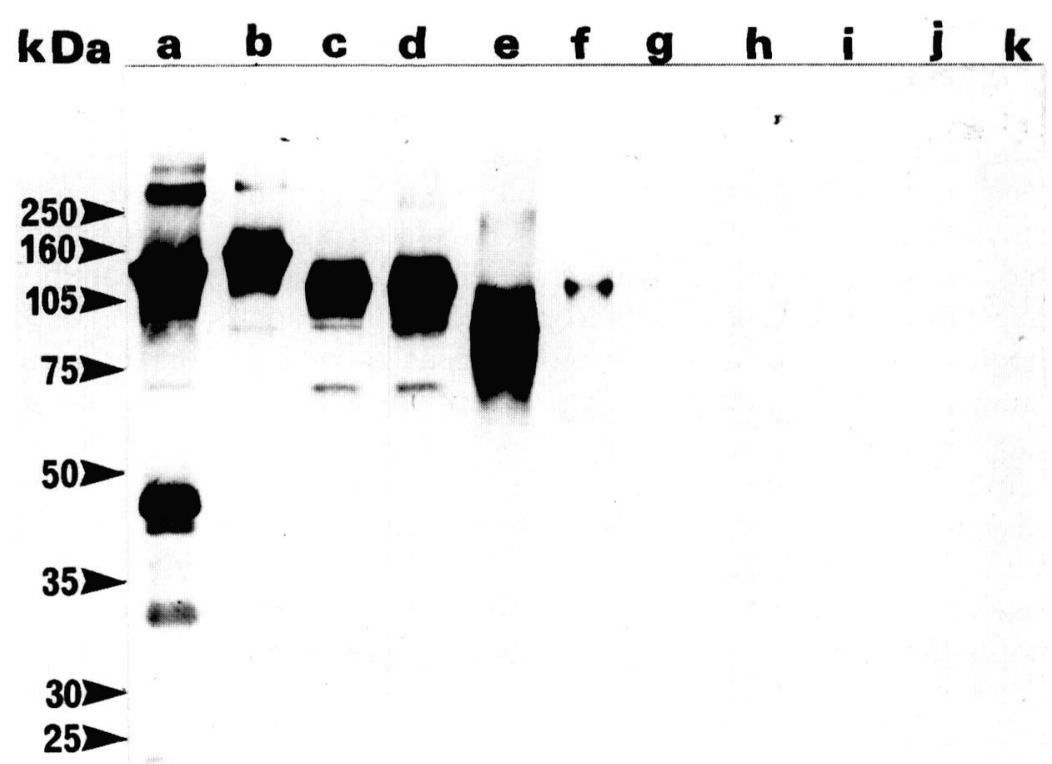

cies. In V. culicis bands were visible above $250 \mathrm{kDa}$, at $170-130 \mathrm{kDA}$ and at $88 \mathrm{kDa}$. Major antigens of $140-$ $100 \mathrm{kDa}, 90 \mathrm{kDa}$ and $65 \mathrm{kDa}$ were identical in P. typicalis and Pleistophora sp. (TB) from T. bubalis. Reactive antigens from $H$. anguillarum were in the region of $250-170 \mathrm{kDa}$ and between 130 and $65 \mathrm{kDa}$. A single band at about $135 \mathrm{kDa}$ was given by $P$. mirandellae. No antigens in common with $T$. bominis were revealed by antiserum 443 in Pleistophora sp. (LS) from L. setiferus, Glugea anomala, Loma acerinae, S. lophii or E. cuniculi. Serum from the AIDS patient was non-reactive on $T$. hominis antigens even at 1:10 dilution.

\section{DISCUSSION}

$I^{n}$ n the present study all the microsporidia investigated were found to have unique protein profiles. Some epitopes of immunogenic antigens were common to Trachipleistophora, Vavraia, Heterosporis and Pleistophora but none of these were shared by the remaining genera, Glugea, Loma, Spraguea and Encephalitozoon, as revealed in Western blots. There was also no reactivity with Pleistophora sp. (LS) from the shrimp L. setiferus, suggesting that this species does not belong to the genus Pleistophora and should be assigned to another genus after morphological re-examination.

Comparison of the ELISA and Western blot results obtained with mouse anti- $T$. hominis sera revealed some anomalies. H. anguillarum, P. typicalis and Pleistophora sp. (TB) gave strong profiles in Western blots but were negative or of very low titre by ELISA. The close relationship between $P$. typicalis and Pleisto- phora sp. (TB) indicated by phylogenies based on $16 \mathrm{~S}$ rDNA (Cheney et al., 2000; Nilsen, 2000) was confirmed by their very similar profiles in Western blots (Fig. 2). Unfortunately the SDS PAGE profile of Pleistophora sp. (TB) was not sufficiently clear to support this. P. mirandellae gave an ELISA titre of $1: 800$, greater than that of $P$. typicalis (1:400) yet there was barely a reaction in the Western blot, even though the SDS PAGE profile, a duplicate of that which was blotted, revealed a good range of proteins. Furthermore Pleistophora sp. (LS) and the Encephalitozoon spp. were moderately positive by ELISA but totally negative in the Western blot. Some of the low titres in the ELISA could have occurred because spores were dislodged from the plastic walls of the ELISA plates during processing. We conclude that the ELISA with serum 483 simply indicated that there was strong homologous reactivity and very little heterologous reactivity, without accurate differentiation of the other species. The Western blot results are considered to be more reliable because the amount of protein applied to the gels was adjusted to $0.5 \mu \mathrm{g}$ for each species, making each profile comparable and because they support the phylogenetic relationships indicated by sequences of the 16S rRNA gene (Cheney et al., 2000; Nilsen, 2000) and of the RPB1 gene (Cheney et al., in press). The $16 \mathrm{~S}$ rDNA phylogenies showed that the species which were strongly cross reactive in the present Western blot results are more closely related to one another than any of these are to Pleistophora sp. (LS) or to the genera Glugea, Loma and Spraguea. These relationships were upheld in a phylogeny based on sequences of the A-G region of the largest subunit of RNA polymerase (RPB1) (Cheney et al., in press). 
Mouse serum 443 used for Western blotting was the only serum that had been obtained after i.p. inoculation of spores in PBS. In other cases spores had been administered in adjuvant. Intraperitoneal inoculation has been demonstrated as a route of infection in athymic mice (Hollister et al., 1996). It is likely that in mouse 443 there had been an active, though transient, infection and the serum would have contained antibodies specific for internal spore antigens as well as antigens of the spore coat. This is supported by the greater number of bands revealed in Western blots by serum 443 than by the other sera. Also, as mouse serum 443 was used for Western blotting of proteins from the range of microsporidian species, while serum 483 was used in the ELISA tests against these species, the results are not strictly comparable. In spite of the differences, it is clear that $T$. hominis can be differentiated from closely related microsporidia by its unique SDS-PAGE profile and that highly specific antisera raised to T. hominis could be used to screen muscle biopsies from AIDS patients with myositis to detect early infections and determine whether or not $T$. hominis is involved in the pathology. Such sera would also differentiate $T$. hominis from the other microsporidia which have caused myositis in AIDS patients i.e. Pleistophora sp. (Ledford et al., 1985) and Brachiola vesicularum (Cali et al., 1998).

Serum from one patient, with severe myositis due to $T$. hominis, who was in the terminal stages of AIDS, was mildly reactive on $T$. hominis antigen by ELISA but non-reactive on Western blots. In a previous study of an AIDS patient with $E$. bellem, from whom serum samples had been kept over a period of four years, there had been a marked drop in antibody level in the terminal stages of AIDS, as revealed by Western blotting of culture-derived spore antigens (Hollister et al., 1993): most of the characteristic proteins of this species shown by the serum samples taken earlier in the patient's illness were no longer recognised by the last sample. In the description of $E$. hellem which was differentiated from E. cuniculi by SDS-PAGE and Western blotting (Didier et al., 1991), sera from three patients with keratoconjunctivitis due to $E$. hellem were tested on SDS-PAGE protein profiles of in vitro culture-derived spores of $E$. hellem. Serum from one patient who was at a slightly earlier stage of AIDS reacted strongly against the $E$. hellem protein profiles, whereas the reactions of the sera of the other two patients, who were in the terminal stages of AIDS, were much weaker. Although these sera were derived from separate individuals, whose immune responses would not have been identical, the results are in accord with the decline in antibody level, which was tracked by Hollister et al. (1993) in one patient, as AIDS progressed. These results suggest that late stage sera might not be useful in diagnosis of microsporidial infections such as $T$. bominis or $T$. anthropophthera, as these infections are only likely to be problematic (and detected) in the terminal stages of AIDS. However, should $T$. hominis be detected in AIDS patients in future, retrospective examination of sera obtained at an earlier stage of AIDS might reveal high levels of specific antibodies. Such sera would be valuable in detection of $T$. hominis antigen in biopsies or as a control in serological surveys of patients with myositis, using the patient's sera against culture derived $T$. hominis antigen.

\section{ACKNOWLEDGEMENTS}

Whe authors would like to thank the following people for provision of spores of the microsporidia used in this study. Drs J.J. Becnel ( $V$. culicis), J.V. Maddox (V. mesnili), K. McKenzie (P. hippoglossoideos), R.M. Overstreet (Pleistophora sp. LS and FA), M. Pekkarinen ( $P$. mirandellae and L. acerinae), E. Weidner ( $S$. lophi $i)$, H. Yokoyama ( $H$. anguillarum) and $\mathrm{R}$. Turner ( $P$. typicalis). We are also grateful to Dr S.W. Feist and M. Longshaw for assistance in collection of Taurulus bubalis and Dr B. Currie for provision of serum from the patient with the T. hominis infection. The work was funded by the Medical Research Council, UK (Grant No. G9603050PB).

\section{REFERENCES}

Buskila D. \& Gladman D. Musculoskeletal manifestations of infections with human immunodeficiency virus. Review of Infectious Diseases, 1990, 12, 223-235.

Cali A., Takvorian P.M., Lewin S., Rendel M., Sian C.S., WitTNER M., KeOhANE E. \& WeIss L.M. Brachiola vesicularum n.g., n.sp., a new microsporidium associated with AIDS and myositis. Journal of Eukaryotic Microbiology, 1998, 45, 240-251.

Canning E.U. Microsporidia, in: Principles and Practice of Clinical Parasitology. Gillespie S.H. \& Pearson R.D. (eds), John Wiley, England, 2001 (in press)

Cheney S.A., Lafranchi-Tristem N.J., Bourges D. \& Canning E.U. Relationships of microsporidian genera, with emphasis on the polysporous genera, revealed by sequences of the largest subunit of RNA polymerase II (RPB1). Journal of Eukaryotic Microbiology, 2000, 48, 111-117.

Cheney S.A., Lafranchi-Tristem N.J. \& Canning E.U. Phylogenetic relationships of Pleistophora-like microsporidia based on small subunit ribosomal DNA sequences and implications for the source of Trachipleistophora hominis infections. Journal of Eukaryotic Microbiology, 2000, 47, 280-287.

Chupp G.L., Alroy J., Adelman L.S., Breen J.C. \& Skolnik P.R. Myositis due to Pleistophora (Microsporidia) in a patient with AIDS. Clinical Infectious Diseases, 1993, 16, 15-21. 
Didier E.S., Didier P.J., Friedberg D.N., Stenson S.M., Orenstein J.M., Yee R.W., Tio F.O., Davis R.M., Vossbrinck C., Millichamp N. \& Shadduck J.A. Isolation and characterization of a new human microsporidian, Encephalitozoon bellem (n. sp.) from three AIDS patients with keratoconjunctivitis. Journal of Infectious Diseases, 1991, 163, 617-621.

Field A.S., Marriott D.J., Milliken S.T., Brew B.J., Canning E.U., Kench J.G., Darveniza P. \& Harness J.L. Myositis associated with a newly described microsporidian, Trachipleistophora hominis, in a patient with AIDS. Journal of Clinical Microbiology, 1996, 34, 2803-2811.

Grau A., Valls M.E., Williams J.E., Ellis D.S., Muntané M.J. \& NaDAl C. Miositis por Pleistophora en un paciente con sida. Medicina Clinica, 1996, 107, 779-781.

Hollister W.S., Canning E.U., Colbourn N.I., Curry A. \& Lacey C.J.N. Characterization of Encephalitozoon hellem (Microspora) isolated from the nasal mucosa of a patient with AIDS. Parasitology, 1993, 107, 351-358.

Hollister W.S., Canning E.U., Weidner E., Field A.S., Kench J. \& MarriotT D.J. Development and ultrastructure of Trachipleistophora bominis n. g., n. sp. after in vitro isolation from an AIDS patient and inoculation into athymic mice. Parasitology, 1996, 112, 143-154.

Ledford D.K., Overman M.D., Gonzalvo A., Cali A., Mester S.W. \& LOCKEY R.F. Microsporidiosis myositis in a patient with the acquired immunodeficiency syndrome. Annals of Internal Medicine, 1985, 102, 628-630.

Lom J. \& PeKkaRINen M. Ultrastructural observations on Loma acerinae comb. nov. (Phylum Microsporidia). Acta Protozoologica, 1999, 38, 61-74.

NiLSEN F. Small subunit ribosomal DNA phylogeny of microsporidia with particular reference to genera that infect fish. Journal of Parasitology, 2000, 86, 128-133.

Shadduck J.A., Meccoli R.A., Davis R. \& Font R.L. Isolation of a microsporidian from a human patient. Journal of Infectious Diseases, 1990, 162, 773-776.

Silveira H. \& CANNING E.U. In vitro cultivation of the human microsporidium Vittaforma corneae: development and effect of albendazole. Folia Parasitologica, 1995, 42, 241250.

Stewart C.G., Van Dellen A.F. \& Botha W.S. Canine encephalitozoonosis in kennels and the isolation of Encephalitozoon in tissue culture. Journal of the South African Veterinary Association, 1979, 50, 165-168.

Vavra J., Yachnis A.T., Shadduck J.A. \& Orenstein J.M. Microsporidia of the genus Trachipleistophora-causative agents of human microsporidiosis: description of Trachipleistophora anthropophthera n. sp. (Protozoa: Microsporidia). Journal of Eukaryotic Microbiology, 1998, 45, 273-283.

Yachnis A.T., Berg J., Martinez-Salazar A., Bender B.S., Diaz L., Rojani A.M., Eskin T.A. \& Orenstein J.M. Disseminated microsporidiosis especially infecting the brain, heart and kidneys: report of a newly recognised pansporoblastic species in two symptomatic AIDS patients. American Journal of Clinical Pathology, 1996, 106, 535-543.

Reçu le 16 septembre 2000 Accepté le 27 novembre 2000 